\title{
EVALUATION OF POINT OF CARE TEST FOR DIAGNOSIS OF HUMAN GIARDIASIS
}

\author{
Manal Abd El Alim Abd El Sattar, Ghada Abd El-Wahed Ismail, Dalia Hosni Abd EI \\ Hamid, Marwa Abd El-Rasoul El-Ashry, and Menna Raafat Asker.
}

Department of Clinical

Pathology, Faculty of Medicine

-Ain Shams, Cairo - Egypt

\section{Corresponds:}

Menna Raafat Ahmed Asker

E.male:

Mennaasker@med.asu.edu.eg

Tel.: 01004281870

Received: 5/3/2019

Accepted: 1/4/2019

\section{ABSTRACT:}

Background: Giardia is a unicellular flagellated parasite infecting wide range of vertebrate hosts, including humans. Infection is usually transmitted through ingestion of cyst stage. Infection occurs worldwide, but particularly affects populations in the developing countries. Giardiasis is usually asymptomatic but, mild to moderate self-limiting diarrhea commonly occurs. In other cases, diarrhea may be severe, prolonged or even life threatening.

Aim of the work: The aim of this study was to assess the value and reliability of the immunochromatographic Giardia strip test (RIDAQUICK)* in a routine diagnostic setting as a point of care test for diagnosis of Giardiasis. The results will be compared to those obtained using conventional microscopy and the ELISA test "reference method" (RIDASCREEN)*.

Subjects and Methods: This cross sectional study was conducted on 30 random stool samples recruited from symptomatic infants and children ( $<10$ years old) of both genders (15 males and 15 females) complaining of gastrointestinal symptoms as diarrhoea, abdominal pain and flatulence. The studied patients were either admitted to inpatient ward of the pediatric hospitals of Ain Shams University or referred from the outpatient clinic. The samples were processed in the Central Microbiology Laboratory, Clinical Pathology Department, Ain Shams University Hospitals from January 2018 till December 2018. All stool samples were subjected to the following: Macroscopic examination of stool samples by naked eye, microscopic examination by conventional methods (Direct wet mount and iodine mount using ordinary light microscopy), immunochromatographic (ICT) Giardia strips and enzyme linked immunosorbent assay (ELISA).

Results Concerning the diagnostic yield of the used diagnostic methods microscopy and ICT compared with ELISA. ICT as diagnostic test was more efficient test than microscopy with higher accuracy (93\%) to detect Giardia in all study individuals. Kappa agreement showed that there was 0.85 (almost perfect agreement between ICT with ELISA findings) and 0.66 (Substantial agreement between microscopy and ELISA).

Conclusion: The use Giardia Antigen detection by ICT was found sensitive and specific for the detection of G. lamblia. They are rapid to perform and do not require experienced staff or special technical equipment, results are obtained within 9-10 min per test.

Key words: ICT, ELISA. 


\section{INTRODUCTION:}

Giardia is a unicellular flagellated parasite infecting wide range of vertebrate hosts, including humans. Infection is usually transmitted through ingestion of cyst stage ${ }^{(1)}$. Infection occurs worldwide, but particularly affects populations in the developing countries. Giardiasis is usually asymptomatic but, mild to moderate selflimiting diarrhea commonly occurs. In other cases, diarrhea may be severe, prolonged or even life threatening ${ }^{(2)}$.

In particular, children in resource-poor countries may be severely affected by Giardiasis, which may lead to significant malabsorption, weight loss and growth retardation $^{(3)}$.

Giardiasis diagnosis is totally dependent on laboratory diagnosis. Fecal examination with classical wet mount is employed as a rapid, cheap, and simple method. Although microscopic examination is the gold standard it offers low sensitivity due to intermittent shedding of parasites and sometimes parasitic load is very low and it is also, highly dependent on the skill and experience of laboratory personnel ${ }^{(4)}$. Commercially available ELISA kits are rapid and effective methods to diagnose Giardiasis through detecting Giardia associated antigens ${ }^{(5)}$. Moreover, rapid immunochromatographic-based kits have been developed and widely used for Giardia antigens detection in stool samples. These lateral flow immunoassays can be accomplished within 10 minutes ${ }^{(6)}$.

\section{AIM OF THE STUDY:}

The aim of this study was to assess the value and reliability of the immunechromatographic Giardia strip test in a routine diagnostic setting as a point of care test for diagnosis of Giardiasis. The results were compared to those obtained using conventional microscopy and the ELISA test.

* R-Biopharm AG: An der Neuen Bergstraße 17, 64297 Darmstadt, Germany, info@,r-biopharm.de

\section{SUBJECTS AND METHODS:}

This study was conducted on 30 random stool samples recruited from symptomatic infants and children ( $<10$ years old) of both genders (15 males and 15 females) complaining of gastrointestinal symptoms suggestive of intestinal giardiasis as diarrhoea, abdominal pain and flatulence. The studied patients were either admitted to inpatient ward of the pediatric hospitals of Ain Shams University or referred from the outpatient clinic. The samples were processed in the Central Microbiology Laboratory, Clinical Pathology Department, Ain Shams University Hospitals from January 2018 till December 2018.

Samples were collected according to the following criteria:

- Inclusion criteria: symptomatic patients with one of the following symptoms (as Stated by CDC,2015)

-Intermittent or continuous diarrhea

-Flatulence

-Greasy stool.

- Abdominal cramps.

- Nausea.

\section{- Exclusion criteria:}

- Duplicate specimen from same patients

- Bloody and /or mucoid diarrhea

The studied population was divided into 2 groups:

- Group (I) (positive microscopy group): 15 samples collected from children suffering from diarrhea and/or other GIT 
symptoms with detection of Giardia cysts/ trophozoites by conventional microscopic stool examination.

- Group (II) (negative microscopy group): 15 samples collected from children suffering from diarrhea and/or other GIT symptoms without detection of Giardia cysts/ trophozoites by conventional microscopic stool examination.

\section{Sampling:}

Stool samples were collected from all cases included in the study. Samples were collected in sterile leak proof, additive free stool cups labelled with the patient's name and date of collection, with strict avoidance of water or urine contamination. Written consent was obtained from the parents or legal guardians of the children. This study was approved by the ethical committee of Faculty of Medicine, Ain Shams University (FMASU MD 418/2017 on 26/11/2017).

All stool samples included in the study were subjected to the following:

- Macroscopic examination by naked eye for consistency, the presence of adult worms, or segments, blood or mucus.

- Microscopic examination by conventional methods (Direct wet mount and iodine mount using ordinary light microscopy) for detection of Giardia or other parasites.

- Examination by immunochromatographic Giardia strips.

- Then stool samples were stored at $20^{\circ} \mathrm{C}$ for detection of Giardia antigen by ELISA.

\section{Statistical analysis of data:}

- Data were coded and entered using the statistical package SPSS version 20.

- Comparisons between groups were done using Chi square test.

- Sensitivity, specificity and kappa agreement measures were done to test the validity of stool analysis and RIDAQUICK (ICT) in relation to RIDASCREEN (ELISA) results.

\section{RESULTS:}

$>$ The studied population was divided into 2 groups:

Group (I) (positive microscopy group): 15 samples collected from children suffering from diarrhea and/or other GIT symptoms with detection of Giardia cysts/ trophozoites by conventional microscopic stool examination. Their age ranged from 14 month to 8 years, with a mean of 5 years, 8 cases $(8 / 15,53 \%)$ of them were females and 7 cases $(7 / 15,47 \%)$ were males with female/male ratio 1.1 .

Group (II) (negative microscopy group): 15 stool samples collected from children suffering from diarrhea and/or other GIT symptoms without detection of Giardia cysts/trophozoites by conventional microscopic stool examination. Their age ranged from 16 month to 8 years, with a mean of 5.5 years, 7 cases $(7 / 15,47 \%)$ of them were females and 8 cases $(8 / 15,53 \%)$ were males with female/male ratio 0.9 . 
Table (1): ELISA readings for detection of Giardia among both studied groups.

\begin{tabular}{|c|c|}
\hline $\begin{array}{c}\text { positive microscopy group } \\
(\mathrm{n}=15)\end{array}$ & $\begin{array}{c}\text { Negative microscopy group } \\
(\mathrm{n}=15)\end{array}$ \\
\hline 2.55 & 0.05 \\
\hline 2.67 & 2.63 \\
\hline 2.33 & 0.06 \\
\hline 2.54 & 0.04 \\
\hline 2.61 & 0.05 \\
\hline 2.42 & 2.7 \\
\hline 2.66 & 2.53 \\
\hline 2.3 & 0.06 \\
\hline 2.7 & 0.05 \\
\hline 2.66 & 0.04 \\
\hline 2.76 & 0.05 \\
\hline 2.25 & 2.34 \\
\hline 2.5 & 2.56 \\
\hline 2.68 & 0.06 \\
\hline 2.65 & 0.05 \\
\hline
\end{tabular}

Negative control reading $=0.05$ (valid if $<0.2)$

Positive control reading $=2.22$ (valid if $>0.8)$

Cut off $=$ extension of negative control $+0.15=0.05+0.15=0.2$

Result is considered Positive if it's reading $>10 \%$ more than the cut off $=0.2+0.02=0.22$

Result is considered negative if it's reading $>10 \%$ less than the cut off $=0.2-0.02=0.18$

Table (2): Results of ICT and ELISA in detection of Giardia among both studied groups.

\begin{tabular}{|c|c|c|c|c|c|c|c|}
\hline \multirow{2}{*}{} & \multicolumn{3}{|c|}{ positive microscopy group $(\mathrm{n}=15)$} & \multicolumn{3}{c|}{ Negative microscopy group $(\mathrm{n}=15)$} \\
\cline { 3 - 8 } & \multicolumn{3}{|c|}{ ELISA } & \multicolumn{4}{c|}{ ELISA } \\
\cline { 3 - 8 } & $+\mathrm{ve}$ & $-\mathrm{ve}$ & Total & + ve & -ve & Total \\
\hline ICT & $+\mathrm{ve}$ & 15 & 0 & 15 & 4 & 1 & 5 \\
\hline & -ve & 0 & 0 & 0 & 1 & 9 & 10 \\
\hline & Total & 15 & 0 & 15 & 5 & 10 & 15 \\
\hline
\end{tabular}

ELISA showed positivity in 20 cases of suspected Giardiasis (15positive microscopy and 5 negative microscopy) among them 19 cases were positive with ICT (15 positive microscopy and 4 negative microscopy) while 1 case was positive with ELISA alone, and another case was positive by ICT alone (Table 2).

Table (3): Diagnostic yield of microscopy and ICT in comparison with ELISA in all study cases $n=30$

\begin{tabular}{|c|c|c|}
\hline & Microscopy & ICT \\
\hline Sensitivity & $75 \%$ & $95 \%$ \\
\hline Specificity & $100 \%$ & $90 \%$ \\
\hline PPV & $100 \%$ & $95 \%$ \\
\hline NPV & $66 \%$ & $90 \%$ \\
\hline Accuracy & $83 \%$ & $93 \%$ \\
\hline Kappa & 0.66 & 0.85 \\
\hline
\end{tabular}

* Key for Kappa:

- $<0$ Poor agreement.

- 0.01-0.20 Slight agreement.

- 0.21-0.40 Fair agreement.

- 0.41-0.60 Moderate agreement.

- 0.61-0.80 Substantial agreement.

- 0.81-1.00 Almost perfect agreement. 


\section{Evaluation of point of care test for diagnosis of human giardiasis}

Concerning the diagnostic yield of the used diagnostic methods microscopy and ICT compared with ELISA. ICT as diagnostic test was more efficient test than microscopy with higher accuracy (93\%) to detect Giardia in all study individuals. Kappa agreement showed that there was 0.85 (almost perfect agreement between ICT with ELISA findings) and 0.66 (Substantial agreement between microscopy and ELISA) (Table 3).

\section{DISCUSSION:}

Infectious diarrhea is a major cause of death in children under 5 years old in developing countries. Unsafe water supplies and inadequate levels of sanitation and hygiene increase the transmission of diarrheal diseases. The etiological agent of Giardiasis, Giardia duodenalis (syn. G. intestinalis, G. lamblia) is one of the most prevalent intestinal protozoan flagellates infecting humans. The life cycle of Giardia species is simple and includes both trophozoite and cystic forms ${ }^{(7)}$.

Giardiasis has various routes of transmission through swallowing of Giardia cysts found in contaminated food or water. Cysts are instantly infectious once they leave the host through faeces. Swallowing as few as 10 cysts may cause infection $^{(8)}$.

The aim of the present work was the evaluation of ICT methods for diagnosis of human infection with Giardia in relation to microscopy and ELISA as the reference test.

A factor complicating the comparative evaluation of various diagnostic methods is the absence of a true reference standard. Usually, the reference standard is based on microscopic pathogen detection, a method that is difficult to standardize because it can be false-negative for cases with a low parasite density or when intact microorganisms are absent and the sensitivity of microscopy depends on the number of faecal samples examined and may be reduced due to the intermittency of the pathogen secretion in stool ${ }^{(6)}$.

The advantage of ELISA is the possibility to analyse single faecal sample as well as stored/frozen samples, unlike microscopy ${ }^{(\mathbf{9})}$.

According to Soares and Tasca, ${ }^{(10)}$, the ELISA provides suitable sensitivity and specificity, with a relevant cost-effectiveness in the clinical diagnosis, since the result is fast. Besides that, the methodology is useful in situations of outbreaks in endemic areas, where the demand of tests is high. Accordingly, in our study we considered it as the reference method.

In the present study, all stool samples were examined aiming at detection of Giardia coproantigen. This was done using the commercially available immunochromatography (ICT) RIDAQUICK and enzyme linked immunosorbent assay (ELISA) RIDASCREEN kit, for detection of Giardia lamblia antigen in faecal specimens.

A total of 20 cases were positive for Giardia by the ELISA (Giardia positive group) including 15 cases in group I and 5 cases in group II. Considering ELISA as the reference test for diagnosis of Giardia infection, the sensitivity of stool examination was $75 \%$ as 15 cases out of the 20 diagnosed by the ELISA were diagnosed by microscopy. The specificity of stool analysis was $100 \%$.PPV was $100 \%$ and NPV was $66 \%$ with $83 \%$ accuracy (Table 3 ).

The decreased sensitivity of a single stool examination for diagnosing giardiasis is primarily due to the fact that Giardia parasites are not shed in the stool on a consistent basis and that their numbers vary from day to day ${ }^{(\mathbf{1 1})}$. Moreover, presence of the parasite at very low levels may offer another explanation for this low sensitivity of stool examination ${ }^{(\mathbf{1 2})}$. In addition to this, as acute infections with $G$. lamblia resolve, 
the number of organisms shed in the stool varies dramatically and the number of cysts passed by patients varies from day to day and week to week ${ }^{(\mathbf{1 3})}$.

Thus, relatively low sensitivity of single stool examination is a reflection of low parasite numbers or intermittent shedding of organisms. This means that at least two independently collected stool specimens need to be submitted for stool examination to obtain a diagnostic sensitivity greater than $90 \%$. But, more than one stool sample is not easily feasible to be collected from patients attending outpatient clinics as it is burdensome to patients. Also, false negative results are likely to be observed due to insufficient sampling ${ }^{(14)}$.

Moreover, microscopic examination must be carried out by a trained technologist. Also, the microscopic examination time per slide is lengthy because the visualization of two to three hundred fields is recommended ${ }^{(\mathbf{1 5})}$.

Regarding ICT, The entire 15 samples included in group I; that were positive by parasitological examination were also positive by ICT and by ELISA.

While, in group II $(\mathrm{n}=15)$ Giardia coproantigen was detected by ELISA and ICT in 4 cases $(20 \%)$ of patients included and one sample was positive by ICT and negative by $\operatorname{ELISA}(5 \%)$ and interestingly, one was positive by ELISA and negative by ICT $(5 \%)$. This discrepancy might probably occur due to non-homogeneous distribution of the parasites in the stool sample according to RIDASCREEN manufacturer instructions.

Concerning the diagnostic yield of ICT compared with ELISA.ICT was more efficient test than microscopy with the higher accuracy (93\%), NPV (90\%) and sensitivity (95\%). But, lower specificity (90\%) and PPV (95\%) compared to microscopy. However, there was almost perfect kappa agreement between ICT with ELISA (Table 3).
Garcia and Garcia ${ }^{(\mathbf{1 6})}$ also, tested ICT Giardia rapid test (SIMPLE-READ Giardia rapid assay; Medical Chemical Corp.) on 210 specimens examined, 106 were known positive for Giardia based on microscopic examination as the reference method and reported a sensitivity of $97.2 \%$ and a specificity of $100 \%$.

Antigen detection by the commercially available RidaQuick assays was found sensitive and specific for the detection of $G$. lamblia. They are rapid to perform and do not require experienced staff or special technical equipment, including the time for sample preparation, results are obtained within 9-10 min per test, like other immunochromatographic test systems ${ }^{(17)}$.Thus, the RidaQuick assays are an alternative diagnostic means of screening stool samples, particularly for smaller and less well-equipped laboratories ${ }^{(17)}$. Also, it can be used as a point of care testing in the outpatient clinics and hospitals.

\section{Conclusion}

Microscopic examination of stool samples provides a simple, specific and noninvasive method for diagnosis of giardiasis and other parasitic infestations. Examination of the direct wet smear is beneficial for detection of Giardia trophozoites in faecal samples of patients presenting with diarrhoea.

The use of Enzyme Immune Assays (EIAs) for detection of Giardia antigen in faeces of patients suspected to have Giardia infection is a sensitive and non-invasive method for diagnosis. It can be used in combination with microscopic examination in symptomatic patients having repeatedly negative stool samples. Also, the EIAs could be used to confirm the result of microscopic examination of a single stool sample.

Antigen detection by the commercially available RIDA QUICK assay exhibited $(95 \%)$ sensitivity and (90\%) specificity respectively for the detection of G. lamblia. 


\section{Evaluation of point of care test for diagnosis of human giardiasis}

It is rapid to perform and do not require experienced staff or special technical equipment, results are obtained within 910 min per test.

However, both ELISA and ICT tests shouldn't replace the routine microscopic examination of faecal samples for detection of Giardia being the sole method that can detect other parasites that may be present in stool samples in addition to Giardia.

\section{REFERENCES:}

1. Robertson L. (2013): Giardia as a foodborne pathogen. New York. USA: Springer; Introduction to Giardia duodenalis: the parasite and the disease; pp. $1-7$.

2. Hawash Y., Ghonaim M. and Al-Shehri S. (2016): An Improved PCR-RFLP Assay for Detection and Genotyping of Asymptomatic Giardia lamblia Infection in a Resource-Poor Setting: Korean J Parasitol.; 54(1): 1-8.

3. Halliez M. and Buret A. (2013): Extraintestinal and long term consequences of Giardia duodenalis infections: World J Gastroenterol, 19 (47): 8974-8985.

4. McHardy I., Wu M., Cohen R., et al. (2014): Clinical laboratory diagnosis of intestinal protozoa. J. Clin Microbiol.; 52:712-720.

5. Jahan N., Khatoon R. and Ahmad S. (2014): A Comparison of Microscopy and Enzyme Linked Immunosorbent Assay for Diagnosis of Giardia lamblia in Human Faecal Specimens. J Clin Diagn Res.; 8(11): DC04-6.

6. Hawash Y.(2014): Evaluation of an Immunoassay-Based Algorithm for Screening and Identification of Giardia and Cryptosporidium Antigens in Human Faecal Specimens from Saudi Arabia. J Parasitol Res.; 213745.

7. Sylvia A. and Una R. (2017): Cryptosporidium and Giardia in Africa: current and future challenges. parasit vectors , 10:195.
8. CDC, 2015: illness and symptoms of Giardia, parasites-Giardia, www. cdc. gov/ parasites/giardia.

9. Vidal, A. and Catapani, W. (2005): Enzyme-linked immunosorbent assay (ELISA) immunoassaying versus microscopy: advantages and drawbacks for diagnosing giardiasis. São Paulo Med. J. 123 (6), 282-285.

10. Soares R and Tasca T (2016): Giardiasis, an update review on sensitivity and specificity of methods for laboratorial diagnosis. J. Microbiol Methods. Oct; 129:98-102

11. Garcia L., Shimizu R. and Bernard C. (2000): Detection of Giardia lamblia, Entamoeba histolytica/ Entamoeba dispar and Cryptosporidium parvum antigens in human faecal specimens using the Triage Parasite Panel enzyme immunoassay. J. Clin. Microbiol., 38(9): 3337-3340.

12. Amar C., Dear P., Pedraza-Díaz S., Looker N., Linnane E. and McLauchlin J. (2002): Sensitive PCR-restriction fragment length polymorphism assay for detection and genotyping of Giardia duodenalis in human faeces. J. Clin. Microbiol., 40: 446-452.

13. Handoussa A., Helmy M., Hussein E.and El-Nimr H. (2005): Degree of symptoms versus copro-antigen levels in Giardia lamblia infection. J. Egypt. Soc. Parasitol., 35: 69-81.

14. Laurianne T. (2013): Comparison of Lateral Flow Immunoassays to Current Stool Evaluation Methods for the Detection of Giardia and Cryptosporidium. A thesis submitted in partial fulfillment of the requirements for the degree of Master of Science University of Washington, 2013.

15. Garcia L., Arrowood M., Kokoskin E., Graeme P., Dylan R. and Visvesvara (2018): Laboratory diagnosis of parasites from gastrointestinal tract. In: American Socity of Microbiology. Clin Microbiol Rev 31: 25-17.

16. Garcia L. and Garcia J. (2006): Detection of Giardia lamblia antigen in human faecal specimens by a solid phase qualitative immunochromatographic assay. J. Clin. Microbiol., 44 (12):4587-4588. 


\section{Manal Abd El Alim Abd El Sattar, et al.,}

17. Garcia L., Shimizu R., Novak S., Carroll M. and Chan F. (2003): Commercial assay for detection of Giardia lamblia and Cryptosporidium parvum antigens in human fecal specimens by rapid solid-phase qualitative immunochromatography. J Clin Microbiol 41:209-212.

\section{تقييم اختبار شرائط الجيارديا كوسيله سريعه لتشخيص الجيارديات المعوية في البشر. منال عبد العليم عبد الستار، غادة عبد الواحد اسماعيل، داليا حسني عبد الحميد مروه عبد الرسول العشري، منه الله رافت احمد عسكر قسم الباثولوجيا الاكلنيكيه ــ كلية الطب- جامعة عين شمس فئس}

المقدمه:الجيارديا من الطفيليات وحيدة الخلية التي تصيب مجمو عة واسعة من المضيفين الفقاريات. وتحدث العيات العدوى

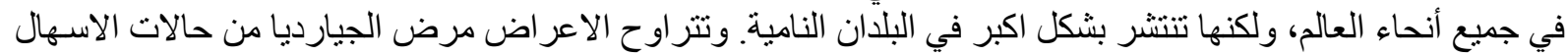

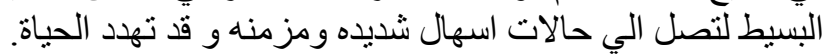

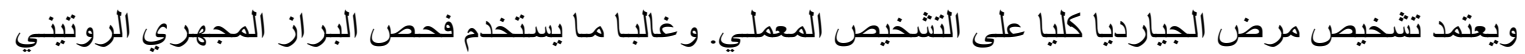

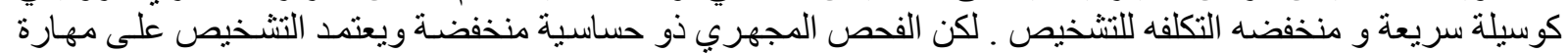

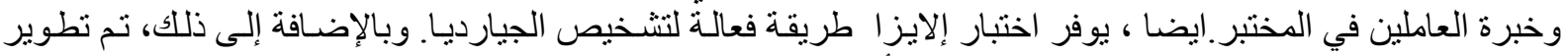
اختبار ات مستندة علي فحص الاستشر اب المنـاعي وأصبحت تستخدم على نطاق واسع للكثف عن عن الجيارديا في في عينات البراز.

الهدف من العمل:الهدف من هذه الدر اسة هو تقييم شر ائط الجيارديا كوسيلة سريعة في التشخيص الروتيني للجيارديا.

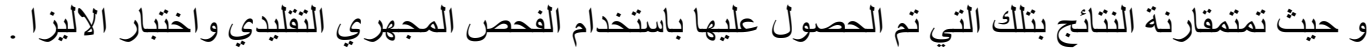

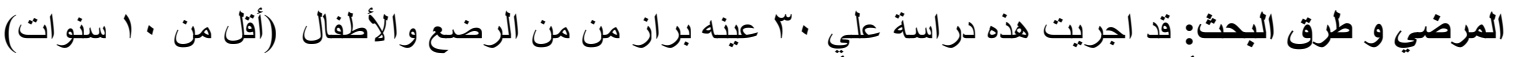

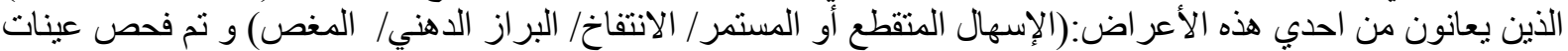

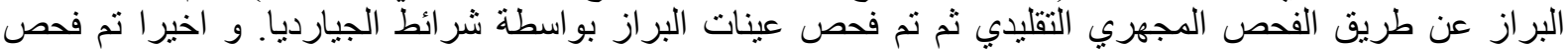
العينات بو اسطة إلاليزا

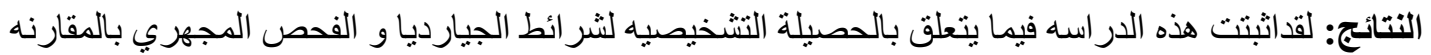

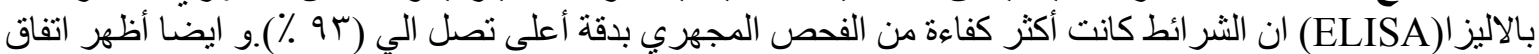

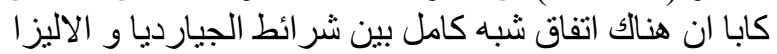

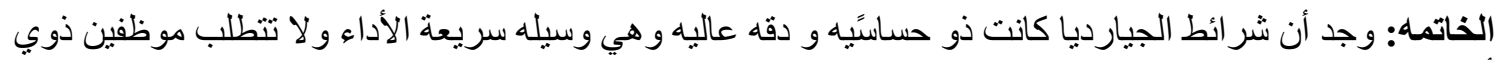

